\title{
JULIO CAMBA A TRAVÉS DE SU EPISTOLARIO
}

Pedro Ignacio LóPEz GARcía

I.E.S.

Nada más interesante -nada, tampoco, más emocionante- para un estudioso de la historia literaria que poder acceder a la intimidad de los trabajos, ideas y sentimientos de uno de sus escritores favoritos. Para ello, el camino más seguro es reunir, ordenar y leer, comparándolos después con lo realizado en sus obras, sus papeles personales: cartas, diarios, notas, apuntes, cuadernos de trabajo. Cuando este escritor, como ocurre con Julio Camba, es alguien extremadamente celoso de su intimidad, poco dado a confidencias, el interés - pienso- es todavía mayor, porque se conservan originales de poquísimas cartas suyas. Era, además, Camba un hombre cordial pero tímido, casi esquivo con los extraños, salvo las mujeres bonitas y los niños. No le gustaba descubrir a cualquiera sus intimidades literarias ni, por supuesto, personales.

\section{El archivo de los Amigos de Julio Camba}

En el mes de julio de 2004 pude acceder por fin, gracias a la buena recepción que tuvo mi libro Julio Camba. El solitario del Palace, primera biografía completa del escritor, a un importante archivo sobre Camba cuya existencia desconocía al igual que prácticamente todos los investigadores que dedican sus esfuerzos a indagar con profundidad y rigor en el conocimiento de la vida y la obra de Julio Camba. 
El profesor Eloy García, de la Fundación Cultural Wellington, con vistas a preparar una bella edición ilustrada de La casa de Lúculo, patrocinada por dicha fundación, me recomendó personal y eficazmente a los hermanos Ángel y Godofredo Chicharro Garcia, propietarios de la taberna Casa Ciriaco (C/ Mayor, $n^{\circ} 84$ ) de Madrid. Poseen estos hermanos en su establecimiento un pequeño museo fotográfico dedicado a Camba y, sobre todo, guardado en carpetas de plástico, un amplio e interesante archivo con todo tipo de materiales referentes al escritor.

Este archivo no es otro que el que reunió durante años el periodista Miguel Utrillo, el cual se conserva hoy, bastante olvidado y en no buenas condiciones de seguridad y de conservación, en un armario metálico de un piso trastero (cuando lo pude ver estaba en obras) propiedad de los dueños de Casa Ciriaco. Este archivo, utilísimo sin embargo, empieza en febrero de 1972, cuando se crea la tertulia de los Amigos de Julio Camba, concluyendo en 1990, año de la muerte de Miguel Utrillo, secretario de la misma. Desgraciadamente no ha tenido continuación. Se ve que, de tantos amigos de Camba como se reúnen hoy todavía una vez al mes en Casa Ciriaco para recordar al escritor, ninguno ha tenido la curiosidad de recuperar esos papeles para estudiarlos o, por lo menos, ampliarlos. En las carpetas que lo componen se reúnen sobre todo artículos de Camba fotocopiados de los periódicos $A B C$ y $E l$ Sol y localizados por Utrillo en la hemeroteca del Casino de Madrid, pero también hay copias de algunas cartas firmadas por él y de otras a él dirigidas, bastantes fotografías, algunas caricaturas y decenas de recortes de prensa. Todo tipo, en fin, de materiales, que de haber conocido con anterioridad a diciembre de 2002, cuando puse el punto final a la biografía del escritor, hubiesen enriquecido mi trabajo en más de un aspecto y, sobre todo, me habrían ahorrado muchas horas de investigación en la Biblioteca Nacional de España y en la Hemeroteca Municipal de Madrid. Pero el nuestro es un país donde los esfuerzos intelectuales, además de difíciles y solitarios, casi siempre son inútiles, porque o no se hacen públicos o no tienen continuidad.

En la colección o archivo de Miguel Utrillo se conservan, en fotocopias casi borradas por el tiempo, pero legibles todavía, algunos documentos autógrafos de Camba que -pienso- son de interés, y que, ante la ingrata pero muy probable perspectiva de que se pierdan para siempre, me apresuro a reproducir y a comentar, aquí, íntegramente.

Ignoro por qué razón Utrillo no hizo uso nunca de estas cartas de Camba en los numerosos artículos periodísticos que dedicó a Julio. O no les concedió excesiva importancia o las reservaba para la feliz ocasión del libro que, sobre la tertulia de los Amigos de Julio Camba, preparó 
durante años y que la muerte le impidió concluir o, lo que es más seguro, ni siquiera comenzar.

Las tres cartas más antiguas que figuran en este archivo no son de Julio sino que están a él dirigidas. Dos de ellas van firmadas por un admirador, el ingeniero de caminos Fernando del Pino; la otra, por la viuda de un amigo y compañero de Camba en $A B C$ : el excelente escritor noventayochista José María Salaverría.

Creo interesante advertir que todas las cartas del archivo de Utrillo han sido escritas, sin excepción, con posterioridad a la Guerra Civil española. ¿Se encontrarán algún día, en archivos privados o en un baratillo de libros y de papeles viejos, otras cartas escritas por Camba o a él dirigidas? Parece poco probable: la Guerra Civil hizo desaparecer muchas cosas, entre ellas bastantes documentos referidos a escritores, en especial los que colaboraban en la prensa, dado el carácter comprometedor de su firma o de sus contenidos. Camba se convirtió en poco tiempo en uno de los más famosos y eficaces enemigos de la República, por lo que cabe suponer el destino de muchos de sus papeles privados.

Las dos tarjetas de Fernando del Pino nos parecen interesantes por ser una breve muestra de las cientos, acaso miles de cartas que recibiría Julio, a lo largo de su vida, de lectores que quisieron felicitarle.

El señor del Pino, tras leer en $A B C$, el 4 de febrero de 1940, el artículo de Camba titulado «La llave y la ganzúa», se apresura a poner las siguientes líneas al escritor:

\section{FERNANDO DEL PINO}

Ingeniero de Caminos

Sr. Don Julio Camba.

Muy Sr. mío:

Su artículo de esta mañana en $A B C$ me ha encantado, porque, burla burlando, con el ingenio en Vd. peculiar, plantea el problema, quizá fundamental, de nuestra civilización.

Como el tema ha sido tratado por mí, en un libro publicado poco antes del comienzo de nuestra tragedia, me permito remitirle un ejemplar, como muestra de consideración a uno de los pocos hombres que se preocupan de estas cosas. ¡Cuidado! Esto no quiere decir que tenga Vd. que leerlo (temo que le pareciera bastante pesado; disto mucho de ser ingenioso), sino, solamente, que no se me ocurre otro modo de expresar mi simpatía al autor de esos párrafos que me han deleitado esta mañana.

Con esto, me es sumamente grato ofrecerme de Vd., atto y s. s., q. e. s. m., Fdo. del Pino.

$\mathrm{S} / \mathrm{c}$ Goya, 31 .

4 Febrero 1940. 
Pero Julio no se encontraba entonces en Madrid sino en Villanueva de Arosa, por lo que diez días después, el 14 de febrero de 1940, Fernando del Pino insiste enviando un tarjetón, esta vez escrito a máquina, al pueblo natal del escritor:

\section{COMPAÑÍA NACIONAL \\ DE LOS FERROCARRILES \\ DEL OESTE DE ESPAÑA}

Sr. Don Julio Camba.

Villanueva de Arosa.

Muy Sr. mío:

La adjunta carta con el libro los envié a $A B C$; de allí me la devolvieron diciéndome que no estaba $\mathrm{Vd}$., y por fin he hablado con el Sr. Mariné, quien me dado su dirección.

E1 artículo a que me refiero se llamaba «La llave y la ganzúa». Le repito mi felicitación por el certero juicio que en él se expresa. Y en paquete aparte recibirá Vd. el ejemplar del libro.

Suyo muy atento s. s.

q. e. s. m.,

Fdo. del Pino.

Ignoro cuál sería el libro enviado por Fernando del Pino a Camba; se trata, probablemente, del titulado La gran decisión, que, con prólogo de un conocido periodista de la época, Luis Araújo-Costa, publicó, en Burgos y en Madrid, Ediciones Fax (sin año, pero en 1936).

De Fernando del Pino, hombre preocupado al parecer por los más graves temas, hemos localizado otros dos curiosos folletos. Uno, de cincuenta y cuatro páginas, titulado ¿Por qué se muere nuestra civilización?, fue el primer premio de la sección de ensayo en el III Certamen Internacional del Círculo de Escritores y Poetas Iberoamericanos, de Nueva York (octubre de 1963). Se publicó en Madrid en 1965. Otro folleto, de cuarenta y ocho páginas, con el título Destino de Europa, fue antes una conferencia leída en el Colegio Mayor San Agustín y se publicó también en 1965.

¿Cuál es el artículo que gustó tanto al señor del Pino y qué cosas dice Camba en él? "La llave y la ganzúa» es uno de esos pequeños pero bien escritos trabajos de Camba, resueltos en apenas cuatro o cinco párrafos, todos breves y de casi idéntica extensión. Tiene interés, a pesar de su brevedad, porque una vez más, desde la modestia (aparente) de sus pretensiones, con la sencillez inimitable de su estilo, consigue decir cosas importantes y hasta trascendentes: 


\section{LA LLAVE Y LA GANZÚA}

Debería hacerse una ley que, por un período de muchos años, prohibiese en absoluto el progreso material de la Humanidad y con la que se pudiera perseguir a todos los investigadores de laboratorio, así como en la Edad Media se perseguía a las brujas. De esta manera se le daría alguna ventaja al progreso moral, que, como es sabido, corre siempre mucho menos que el material, y el desequilibrio entre uno y otro no tendría nunca las consecuencias catastróficas que está teniendo en nuestra época.

Sí, señores. Yo cerraría todos los laboratorios, porque tengo para mí que todo lo que está ocurriendo hoy en el mundo no es más que el resultado de la enorme desproporción que existe entre sus valores materiales y sus valores espirituales. Estará muy bien el dominar las fuerzas de la Naturaleza, pero, primero, habrá que dominar las propias pasiones, o de lo contrario el hombre será como un chimpancé al que le hubiesen puesto una ametralladora en las manos.

Ya sé que no lograré convencer a nadie. El hombre actual, envanecido con los adelantos materiales de que disfruta y considerándolos como un exponente de su progreso moral e intelectual, se imagina vivir en un siglo muy superior, por ejemplo, al de Pericles; pero lo uno no tiene absolutamente nada que ver con lo otro. Por mi parte yo he visto a más de un mono tirar al blanco, montar en bicicleta, guiar un automóvil y servirse de los inventos modernos como un ciudadano cualquiera de Nueva York o de Chicago, y ello no mejoró en nada mi concepto de los monos ni empeoró tampoco de un modo sensible el que me había formado sobre los ciudadanos neoyorquinos o los chicagüenses.

Supongo que todo el mundo coincidirá conmigo en la creencia de que, mientras el hombre no sea un semidiós, resultará sumamente peligroso el poner en sus manos la llave de los rayos y los huracanes; pero la cuestión no es ésta. La cuestión es que hay ya quien le atribuye unas dotes semidivinas por el hecho de tener en su poder, si no precisamente esa llave, por lo menos una ganzúa que la sustituye, y yo pienso todo lo contrario, esto es, que la ganzúa de los rayos sólo le sirve al hombre para poner en evidencia su triste inferioridad.

Indudablemente, los antiguos tenían un concepto muy superior al nuestro de la armonía y el equilibrio del mundo. Ellos sabían muy bien qué clase de adelantos elevaban nuestra condición y nos aproximaban a Dios, y qué clase eran más bien producto de pactos con el diablo. Muchos de los inventos que sirven de base a nuestra civilización se los debemos a ellos; pero hay otros que ellos, indudablemente, no hubiesen permitido nunca. 
Comprendemos que interesara este artículo al señor Fernando del Pino, pues demuestra cómo preocupaba también a Camba el hecho de que el hombre, demasiado cerca del animal, muchas veces, tuviera ahora en sus manos, como dice con evidente gracia expresiva, entre admirado y preocupado, «la llave de los rayos y los huracanes». Estamos en febrero de 1940, Europa lleva ya seis meses de guerra y se empieza a ver con horror que la reciente tragedia española ha sido apenas un ensayo general con casi todo de lo que iba a venir después.

Mucho más interesante es la siguiente carta que reproducimos a continuación y que inmediatamente comentamos. José María Salaverria, un escritor excelente pero de segunda fila, entre los de la llamada Generación del 98, aunque también uno de los mejores y más famosos periodistas españoles del primer tercio del siglo, acababa de fallecer. Camba, quien le conoció y fue su amigo, escribe con este motivo un artículo que emocionó a la viuda del escritor vasco. Fotocopiada en una de las carpetas del archivo de Miguel Utrillo hemos encontrado esta carta, breve pero sentida, cuyo original al parecer conservó Camba y que debió de regalar a Utrillo o a otro cualquiera de sus amigos. En un sobre con orla negra de luto, dirigido al «Señor Don Julio Camba. Escritor», a Villanueva de Arosa (Galicia), la viuda de Salaverría introdujo una tarjeta, también con orla de luto, por cuyas dos caras escribió con hermosa letra lo siguiente:

Madrid, 2 de mayo de 1940.

Señor Don Julio Camba.

Villanueva de Arosa.

Mi estimado amigo:

Aún no le había agradecido a usted su cariñoso telegrama y me encuentro con su precioso artículo dedicado a mi muy querido José $\mathrm{M}^{\mathrm{a}}$ (q. e. p. d.). Muchas gracias, amigo Camba. El artículo me ha encantado por lo sentido y justo. Su frase «Ha muerto como un soldado raso, aunque todos le reconocíamos categoría de Capitán General», es un verdadero regalo para mí.

Esperando tener ocasión de repetirle de palabra todo mi reconocimiento, téngame como su más devota amiga que e. s. m.

Amalia G. de Salaverría.

Tiene razón la viuda de Salaverría en afirmar que el artículo de Camba -«Salaverría y su atmósfera», $A B C, 30-I V-1940$ (no recogido en libro)- es, aunque breve, una sensible despedida al escritor vasco. Se nos descubre Julio aquí como un excelente autor de evocaciones necrológicas (sería interesante comparar esta página de Camba con las firmadas entonces por otros escritores y periodistas): 


\section{SALAVERRÍA Y SU ATMÓSFERA}

Lectores asiduos de Salaverría, teníamos todavía en los labios la miel de un artículo suyo cuando nos sorprendió la noticia de su muerte. Ello significa que el gran sembrador de ideas ha muerto al pie del cañón, como solía decirse, de una manera figurada, en aquellos días felices en los que el morirse literalmente al pie del cañón constituía un hecho excepcional e inusitado. Ha muerto al pie del cañón, defendiendo los ideales de toda su vida, y ha muerto como un soldado raso, aunque todos le reconocíamos categoría de capitán general.

Yo le había visto no hacía aún mucho tiempo, en su hermosa ciudad de San Sebastián, y había hablado diferentes veces con él. A eso de las doce y media o la una de la tarde, cuando Salaverría había escrito ya su artículo y yo andaba aún buscando pretexto para no escribir el mío, solía encontrármelo en la avenida y era muy raro el que no echásemos un párrafo.

-¿Qué se dice por ahí? -solía preguntarme Salaverría-. Cada vez ando peor del oído y por eso no frecuento ninguna tertulia...

Pero si Salaverría no frecuentaba las tertulias porque le molestaba el oír mal lo que se decía en ellas, yo había dejado de frecuentarlas, precisamente, por todo lo contrario, esto es, por oírlo demasiado bien, y nunca podía satisfacer la curiosidad de mi ilustre amigo, curiosidad, que, por otra parte, consideré siempre tan sólo como una mera fórmula de cortesía. ¿Qué le importaba, en efecto, a Salaverría el cotilleo de las tertulias literarias o los corrillos políticos? El gran escritor estaba, indudablemente, muy por encima de todos los chismes y murmuraciones de café y, si no fuese sordo por defecto, hubiese tenido que hacerse el sordo por virtud.

-No se dice nada, Salaverría -le contestaba yo-. No se dice nada que valga la pena de ser repetido.

-Ah! ¿eso es lo que se dice? -exclamaba entonces Salaverría, a quien yo nunca solía gritarle lo bastante-. ¡Muy bien, muy bien! Me alegro mucho...

Y después de un corto diálogo por este estilo, allá se iba el admirable escritor, alto, enjuto, y más tieso que un huso, a pesar de sus sesenta y tantos años. Allá se iba por su camino, con ese aire, un poco ausente, de los hombres que, aun en medio del gentío más apretado, se ve que respiran siempre una atmósfera propia.

Salaverría tenía dos grandes limitaciones para la vida exterior: su dureza de oído y su afección al estómago, que le impedía tomar las pócimas de los cafés, pero la vida que por estas causas dejaba de proyectarse hacia afuera, revestía hacia adentro con noble impulso, y es muy posible que, sin sus achaques materiales, el grande hombre no hubiese 
adquirido nunca la enorme riqueza espiritual que derrochaba a diario en sus escritos. Talento, evidentemente, lo hubiese tenido siempre, pero, después de todo, el talento no es una cosa tan rara como parece a primera vista. Lo raro es el corazón y, a los sesenta y tantos años, Salaverría tenía aún un corazón de niño.

Sencillo, sin erudición impertinente ni confusas divagaciones líricas, tan gratas - por ejemplo- a otro maestro de periodistas, César GonzálezRuano, es difícil encontrar un artículo más justo y delicado a la vez. Camba, sin embargo, no renuncia a cierto humorismo cuando recuerda la sordera de su amigo; algo que, lejos de resultar de mal gusto, nos parece, por contraste con el idealizado recuerdo del escritor, doblemente eficaz.

Seguimos ahora, respetando la cronología, con unas cartas de Julio a su íntimo amigo José Luis Pastora Chorot, quien facilitó copia u original de las mismas, a Miguel Utrillo, en la Navidad de 1979. Se trata de dos cartas, datada la primera el 5 de mayo de 1945, y la segunda, el 1 de julio de ese mismo año. El papel lleva membrete del Avenida Palace Hotel, de Lisboa, residencia entonces de nuestro escritor:

\section{AVENIDA PALACE HOTEL \\ LISBONNE \\ PORTUGAL \\ Mayo 5 de 1945. \\ Querido José Luis:}

Encantado de tener noticias de ustedes, a los que echo tanto de menos. Por cierto que, el día en que se fueron de aquí, yo bajé de mi habitación a las diez y media de la mañana dispuesto a despedirlos con todos los honores, pero, cuando llegué a la portería del hotel, ya habían ustedes desaparecido. Entonces tomé un taxi y me dirigí, raudo y veloz, al Flórida seguro de que, según lo anunciado, no se pondrían ustedes en camino antes de las once, pero, a las once, se conoce que ya estaban ustedes en Alcobaça (aumentativo de alcoba) atracándose de perdices a la cazuela mientras yo, muerto de sueño, bajaba la avenida da Liberdade pensando melancólicamente en la perfecta inutilidad de todos los sacrificios humanos.

Muchas gracias a su madre por las tabletas de Cafintrina que me dejó al irse y que conservo como oro en paño y mis más afectuosos saludos a Mary.

Yo, como Hamlet y como la luz de Ortega, estoy cada día más vacilante respecto a mi veraneo, y todavía no sé si me decidiré a ir por ahí o no. En todo caso, y por si llegara a decidirme, le agradecería a usted que fuese a esperarme a Porto el día de mi llegada y no un día antes como comienzo a temer dado su concepto de la puntualidad. Y, a propósito de [mi] ida a 
Santa Lucía, ¿qué se puede hacer ahí a más de oúr la radio y contemplar ese paisaje sólo comparable a los de Funchal y Río de Janeiro? ¿Hay a proximidad del hotel paseos que no estén muy en cuesta? ¿Existe algún entretenimiento en el pueblo? Y, last but not least, ¿cuál es ahí el precio de una buena habitación con casa de banho?

Esperando que me envíe usted esto, cuando tranquilamente tenga tiempo para ello, y con mis más cariñosos saludos para su madre y para Mary, le abraza, etc., etc., Julio.

La siguiente carta, mucho más breve, también con membrete del Avenida Hotel Palace, de Lisboa, está fechada el 1 de julio de 1945. Dice así:

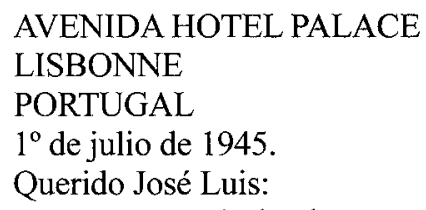

Le pongo a $\mathrm{Vd}$. dos letras antes de irme a Caporina en donde pienso pasar todo el mes de julio, proponiéndome ir a Santa Lucía en el de agosto si Vd., con su influencia todopoderosa, consigue que me reserven ahí una buena habitación a partir del día primero. Claro que esto podrá costarle a Vd. alguna paliza al billar, pero tiene Vd. un mes entero para entrenarse.

Rogándole que me conteste lo antes posible para saber a qué atenerme y con mis más cordiales saludos tanto para su madre y Mari como para Fernando Cort y familia, le abraza su buen amigo, Julio.

P. D.: Como yo vendré a Lisboa por lo menos un par de veces por semana, lo mejor será que me escriba Vd. al Avenida.

Entre los papeles del archivo de Miguel Utrillo no hay original o copia de ninguna otra carta de Camba a José Luis Pastora Chorot. Lo que sí encontramos, fotocopiada en la misma hoja donde figura la carta anterior, es la siguiente dedicatoria autógrafa de Julio, sin duda en el primero de los dos volúmenes de sus OO.CC., publicadas por la editorial Plus Ultra en 1948. La dedicatoria dice así:

A José Luis Pastora, gran amigo y jefe de una familia a la que me considero virtualmente incorporado, dedico, en testimonio de afecto y gratitud, estas obras completas y una corbata azul con pintas blancas.

Julio Camba.

Lisboa, mayo 14 del 1948. 
Se conservan poquísimos libros dedicados por Camba -jamás hemos visto uno solo en nuestras frecuentes visitas a las librerías anticuarias o de lance; tampoco hemos encontrado ninguno en la Casa-Museo Azorín, de Monóvar, o en la de Miguel de Unamuno, en Salamanca (y ambos fueron amigos y admiradores de Camba). Sin embargo, un periodista que trató algo a Julio, Marino Gómez-Santos (Gómez Santos, 2003, 55), reproduce fotográficamente la dedicatoria -bastante fría; parece de compromisoque puso para él nuestro escritor en un ejemplar de La ciudad automática (compárese con la que escribió a su verdadero amigo José Luis Pastora):

A Marino Gómez Santos. Con el afecto y la consideración de su amigo y compañero

Julio Camba.

Madrid. Enero del 1956.

Desconozco si Camba escribió otras cartas a José Luis Pastora. Probablemente no, pues el destinatario se las hubiese facilitado a los Amigos de Julio Camba. Las únicas cuya fotocopia se conserva en las carpetas de Utrillo son las arriba reproducidas íntegramente.

Me parece interesante observar la ilusión de un soltero ya mayor como Camba de intentar incorporarse, virtualmente o no, a una familia quizá numerosa, la obligación de agradecer las atenciones que se tienen con él y, sobre todo, la necesidad de que le ayuden a resolver las pequeñas incomodidades y molestias de la vida cotidiana.

Otras dos cartas muy curiosas, ambas sin fecha pero ya con membrete del Hotel Palace, de Madrid, son las enviadas a Nina, hermana de Félix Moreno de la Cova y que esta señora envió, ignoramos si en original o en fotocopia, pero fotocopia es lo que se conserva en el archivo de Miguel Utrillo, a los Amigos de Julio Camba en diciembre de 1984, año del centenario de nuestro escritor. La segunda de ellas es relativamente extensa para lo que Julio acostumbraba, revelando el cariño e incluso el interés que, sin duda, sintió en cierto momento por Nina:

\section{PALACE HOTEL \\ MADRID \\ Hoy, jueves 28, etc. \\ Querida Nina:}

He sentido la mar no verte ninguna de las dos veces que estuviste en Madrid. Espero que te veré la próxima aunque no sea más que por aquello de que a la tercera va la vencida.

Me han dicho que Carmen Aguilar se ha desgarrado terriblemente una pantorrilla con un clavo al bajar del tren el mismo día en que se marchó a Laredo y que la pobre ha estado fastidiadísima todo este tiempo. En 
cambio tengo las mejores noticias del sabio, quien parece que se ha recuperado de un modo prodigioso y está mejor que nunca. Una de estas noches voy a cenar con él y con Escardó. Si quieres que le diga algo, avísame.

Tu buen amigo que te echa muchísimo de menos

Don Julio.

Una nota manuscrita de Miguel Utrillo, al final del texto, aclara que «el sabio» a quien se alude es el señor Flórez de Lemos.

Como se ve, esta carta no tiene ninguna importancia literaria, pero resulta reveladora del cariño con que trataba Julio, hombre ya maduro, a sus amigas más jóvenes. (Conociendo a Camba hay que suponer que, además de joven, Nina debió de ser una chica bastante bonita).

Algo más larga, aunque tampoco demasiado, es otra carta, esta vez sin fecha pero escrita en un verano bastante caluroso, que Julio envió a Nina. El membrete del papel corresponde de nuevo al Hotel Palace de Madrid. Ofrecemos el texto completo:

\section{PALACE HOTEL (MADRID)}

Nina guapa:

Siento muchísimo el saber que has estado enferma y nada menos que con 40 grados de fiebre (supongo que a la sombra), pero espero que al recibo de esta carta te encuentres ya completamente restablecida y con más vitalidad que nunca.

Por si ello te sirve de consuelo te diré que aquí, en Madrid, para estar a cuarenta grados no necesitamos anginas ni cosa que se le parezca porque a esa temperatura mínima estamos todos constantemente $y$, así como a ti te alivió la penicilina, para nosotros no hay penicilina que valga. Yo me paso el día durmiendo y bebiendo. Duermo siesta de tres y de cuatro horas y bebo cerveza, horchata, limonadas, coca-cola, agua de seltz, etc., etc., con todo lo cual estoy poniéndome tan gordo que, cuando me veas, no vas a saber si yo soy yo o si soy la marquesa de Casa Calderón. Estos últimos días festivos -el domingo y el lunes que era la Virgen de la Paloma-me los pasé en Navalcaide, muy cerca del Escorial, pero tampoco allí tuve fresco. En cambio eché mucho de menos el agua y la luz de que disfruto en el Palace.

Del sabio no sé absolutamente nada. Nuestra cena no se celebró y Escardó supongo que habrá ido a pasar unos días con su mujer y con su niña como tenía pensado. Antes solía encontrármelo en Lhardy, pero ahora Lhardy está cerrado y lo que voy a hacer es llamar uno de estos días a su casa.

Bueno, Nina. Estoy deseando verte y verte tan bien de salud y tan guapa como siempre. Cuídate mucho y no te acuestes demasiado tarde 
porque si no, a lo mejor, te tropiezas un día en un pasillo con la sombra de Don Felipe II.

Tu amigo que te recuerda constantemente Julio.

Pienso que estas cartas, sobre todo la última, ayudan bastante bien a dibujar una imagen real y más cercana de Camba, hombre simpático y cordial, amigo de bromas íntimas, que sabe ponerse a la altura de sus interlocutores y no aburrirlos ni marearlos con arduas cuestiones políticas, filosóficas o literarias, que tan poco han interesado siempre -confesémoslo-a quienes no se dedican con exclusividad a tareas artísticas o eruditas.

¿Cuándo se escribieron estas dos últimas cartas? Pienso que a finales de los años 40 y principios de los 50 , cuando Julio tenía ya entre sesenta y sesenta y cinco años de edad. Ello no impide que, a su manera, intente agradar a las mujeres que le gustan -casi todas mucho más jóvenes que él-; actitud o estrategia muy diferentes de las que solía emplear con sus «enemigos íntimos» (como decía Sebastián Miranda) del sexo masculino. Estas cartas nos descubren a un hombre práctico y, sobre todo, educado, excesivamente sencillo quizá pero simpático y natural, que piensa antes en los destinatarios de tan breves tarjetas que en la posteridad. Camba no posa aquí de escritor profundo y trascendente sino que le interesa mucho más ser simpático y directo, tan eficaz como agradable.

Según una tarjeta cuya fotocopia, casi borrada, se conserva en otra carpeta del archivo de Miguel Utrillo en Casa Ciriaco, y que pudimos reproducir de manera sorprendentemente buena en la parte gráfica, «La maleta de Camba», de la edición de La casa de Lúculo realizada por la Fundación Wellington (López García, 2004, 66), Camba ingresó por primera vez, como huésped del hotel, el 6 de mayo de 1947. Ocupó entonces la habitación 260. Permaneció allí hasta el 19 de junio de ese año. Volvió al hotel el 8 de julio de 1949, ocupando la 182. Cambió luego, el 2 de agosto, a la 485. Ingresó por fin, como huésped fijo, el 13 de abril de 1954, siendo dado de baja como cliente del mismo el 28 de febrero de 1962 , fecha de su fallecimiento. Ocupaba entonces la habitación 383.

Fue don Alfonso Font, director de los hoteles Palace y Ritz, quien tuvo la gentileza de obsequiar, en diciembre de 1973, a los Amigos de Julio Camba con una fotocopia de las fichas de Camba en el famoso hotel madrileño. Documentos inapreciables para nosotros, que nos llevan a datar casi con toda seguridad, en el verano de 1949, las dos cartas de Camba a su amiga Nina, es decir, cuando estaba a punto de cumplir Julio sesenta y cinco años. No debe extrañarnos. Según Virginia Rebollar, hija de la «Sari» y sobrina de Sebastián Miranda, una de las amigas más jóvenes de Camba (conocía al escritor desde niña), con quien he podido 
ponerme en contacto por carta y telefónicamente, a Julio, ya mayor, se le iban los ojos tras las mujeres guapas, especialmente la Condesa de Calimaya (véase la pág. 58 de la sección «La maleta de Camba» de la edición Wellington de La casa de Lúculo). «Ésa sí que le gustaba», me dice Virginia muy expresiva.

Existen muchos testimonios del agrado que le producían a Julio sus numerosas amistades femeninas: María (Marita) Masiá, Isabel Berdegué, incluso niñas como Virginia Rebollar (a quien decía que iba a hacer heredera de sus misteriosas maletas) y Esperanza Ridruejo y, por supuesto, también adolescentes. Sebastián Miranda recuerda, por ejemplo, que en una ocasión, en 1948 ó 1949, cuando Camba se reponía de una enfermedad «pasando las horas en el jardín de mi casa, disfrutando de los días primaverales», coincidía allí diariamente «con la hija de un marqués, maravillosa muchacha de dieciocho años, cuyo padre me había encargado su estatuilla. Al poco tiempo de comenzada la estatua, simpatizaron de tal manera que me costaba un triunfo el obligarla a entrar en el taller para realizar mi trabajo. Y un día la dijo: «Niégate. No seas tonta. Para la birria que te va a hacer, estás mejor aquí» [...] Otra de sus debilidades era Isabelita, la mujer del librero Antonio Berdegué, que cariñosamente se sacrificaba llevándole a última hora la comida a la habitación del Hotel Palace, donde vivió los últimos años» (Miranda, 1975).

Todavía en 1962, poco antes de su muerte, dijo unas reveladoras palabras a Ángel Lázaro:

«Fue hace mes, en la calle del Prado, a la altura del Ateneo. Iba él hacia la plaza de Santa Ana, y nosotros hacia la docta casa.

- ¿Ya no viene usted por aquí? -le preguntamos.

-No, ya no; pero sigo siendo socio. Me han dicho que ahora hay una gran cantidad de muchachas ateneístas, muy bonitas todas. Pero uno ya...

Una chispa brillaba en sus ojos. La misma que destellaba siempre en el soneto que era cada artículo suyo» (Lázaro, 1962).

De su puro amor por los niñas hay testimonios preciosos. En el Epílogo que escribí para la edición ya citada de La casa de Lúculo recordé la siguiente anécdota:

A principios del año 1949 una colegiala llamada Esperanza conoció a un señor mayor, muy amable, en un sanatorio dietético. Cuando los padres de «Pitita» salían de viaje, lo que ocurría bastante a menudo, enviaban a comer a la niña a la clínica del doctor Jiménez. Allí encontró y se hizo amiga en seguida de aquel caballero tan simpático, consiguiendo que revisara sus composiciones literarias de la escuela. Como la chica estaba encantada 
con su colaborador, al final las redacciones fueron escritas casi totalmente por el caballero, el cual permaneció todavía unos meses en la clínica no por problemas de nutrición, sino para reponerse de una rara enfermedad, el «vértigo de Meniére». Aquel hombre tan simpático y amable no era otro que Julio Camba. Nadie advirtió el engaño. ¿Cuántos escritores, de ayer o de hoy, hubiesen superado la prueba de adaptar su estilo a la sintaxis y el vocabulario de una colegiala? «Pitita» Ridruejo guarda todavía con gratitud, dedicado cariñosamente por Julio Camba, un ejemplar de Londres (López García, 2004, 246).

\section{La Biblioteca Nacional de España}

Por desgracia, no se conservan muchas más cartas de Camba. Si las hay no se han hecho públicas o, por el momento, no son accesibles. En mi citada biografía del escritor, publicada a finales de 2003 pero terminada casi un año antes, pude reproducir, íntegramente, tres cartas de las cuatro conservadas en la sección de manuscritos de la $\mathrm{BN}$, procedentes con toda seguridad del archivo de la editorial Biblioteca Nueva. Fue emocionante para mí tener entre las manos esos papeles, por cuanto de Camba apenas se conservan manuscritos. Dije entonces de la letra de Camba que era «clara y elegante, ligera -se ve que redacta con facilidad, casi a vuela pluma-, pero segura. Escritas probablemente sin borrador, no se observa en estas cartas ni una sola tachadura, añadido o enmienda» (López García, 2003, 130).

Estas cartas de Camba a su amigo y editor, José Ruiz Castillo, son también, en su brevedad, de las más curiosas entre las de Julio, aunque quizá las más importantes sean las que envió a Pedro Sainz Rodríguez durante la Guerra Civil española.

Voy a hablar de esas cartas autógrafas con un poco más de detalle del que, por razones editoriales, pude tener entonces. Las cuatro cartas se conservan en la sección de manuscritos de la BN. Están dirigidas a un tal Castillo, es decir, a José Ruiz Castillo. La signatura es: 22.600, 201-204. La numerada con el 201, escrita en papel con orla de luto, dice así:

Querido Castillo:

Le envío a $\mathrm{V}$. el recibo que me pide, un retrato maravilloso y esa lista de mis libros que tengo grandísimo interés en que salga.

No sé si habrá algo que corregir en Un año en el otro mundo. Lo revisaré cuanto antes y, en todo caso, le mandaré un ejemplar con las modificaciones que se me hayan ocurrido. 
Yo salgo muy poco. Estoy gestionando el pasaporte para irme a Alemania y creo que no permaneceré aquí arriba de quince días. Me gustaría verle a $\mathrm{V}$. antes de marchar.

Siempre suyo,

Julio Camba.

Madrid, febrero 17 de 1920.

La carta numerada con el 202, también con orla de luto, declara:

Querido Castillo:

Me ha dicho [José García] Mercadal que quiere V. hacer una segunda edición de Un año en el otro mundo en iguales condiciones que la primera.

Si V. puede darme las quinientas pesetas antes del viernes, 13, entonces yo le concedo a $\mathrm{V}$. desde luego la autorización requerida. Me encuentro en un gran apuro y 500 pesetas valen ahora para mí tanto como mil o mil quinientas en circunstancias normales.

Le agradeceré que me conteste a la mayor brevedad.

Su buen amigo y compañero,

Julio Camba.

S / c Plaza de Jesús, 3.

Esta carta, sin fecha, aunque en la BN ha sido catalogada con el número 202, estimo que se trata en realidad de la 201, siendo la transcrita primero la segunda que escribió Camba.

La carta autógrafa número 203 es un folio doblado. Leemos en ella:

Querido Castillo:

Muchas gracias por su Pirandello.

Como hago tan pocos artículos, no sé si tendré ocasión de complacer a V., aunque pondré en ello mi mejor voluntad. En cambio he hecho para La Nación de Buenos Aires una larga crónica sobre Freud que debe de estar al salir.

De Nueva York me envían The Literary Digest correspondiente al mes de febrero y cuyo primer artículo, con grandes y fantásticos dibujos, está dedicado $A$ year in the other world (Un año en el otro mundo) con especial mención de su editor y de la Biblioteca Nueva. Es una revista de las más importantes y tiene una difusión enorme.

Conste que haré lo posible por citar al pelmazo de Pirandello y que todo es cuestión, o de que yo escriba unos cuantos artículos durante este mes, o de que el propio Pirandello me sugiera uno.

Siempre muy suyo

Julio Camba.

Hoy, viernes. 
Podemos datar esta carta con bastante precisión, por cuanto Biblioteca Nueva sólo editó un libro de Luigi Pirandello, la novela El difunto $\mathrm{Ma}$ tías Pascal, en versión castellana y prólogo de Rafael Cansinos Assens, en el año 1924, volumen de 375 páginas.

La última carta custodiada en la BN, y numerada con el 204, es un folio de color rosa que ha sido cortado cuidadosamente por la mitad. Tampoco está datada. No la reproduje en mi biografía del escritor. Se ofrece aquí, por primera vez, íntegramente:

Querido Castillo:

Todavía no he visto mi libro. ¿Sería V. tan amable que me enviase unos cuantos ejemplares?

Yo estoy aquí desde hace cinco o seis días pero pienso largarme pronto con viento fresco. Si antes pudiese echar un parrafito con V., me alegraría mucho.

Muy suyo,

Julio Camba.

$\mathrm{S} / \mathrm{c}$ Pontejos 2, segundo

\section{EI archivo de Eduardo Marquina}

Recientemente mi querido maestro, el profesor Andrés Amorós, ha podido publicar una carta de Camba al poeta Eduardo Marquina. Es una nota brevísima, de apenas tres líneas (Amorós, 2005, 426). La reproducimos a continuación, a pesar de su relativo interés y de haber sido ya publicada, por completar este trabajo y para advertir el contraste que supone con las que Camba envió a Nina o a José Luis Pastora:

Mi buen amigo:

Le agradeceré me envíe su tomo de traducciones de Baudelaire. Hablaré de ellas en El País.

Mil gracias y mande a su buen amigo y compañero

Julio Camba.

$\mathrm{S} / \mathrm{c}$ Fomento, $27,4^{\circ}$.

\section{El archivo de Rubén Darío}

También a su admirado Rubén Darío envió una carta muy breve, sin fecha pero de hacia 1910, en París, solicitándole original para un periódico o revista que no hemos podido identificar. Esta carta la reproduce Dictino Álvarez en su libro Cartas de Rubén Dario. (Epistolario inédito del poeta con sus amigos españoles), Madrid, Taurus, 1963, pág. 158: 
Mi ilustre amigo:

¿Se han acordado ustedes de encargar mis cuartillas? Si las tiene $V$. ahí déselas a la chica y, si no, envíelas V. a la imprenta con las instrucciones necesarias. La chica le abonará a V. lo que sea.

Un millón de gracias y perdónele $\mathrm{V}$. a un pobre periodista como yo el atrevimiento de pedirle cuartillas a un tan gran poeta como V.

Salude V. de mi parte al pequeño Rubén y a su mamá.

¿Cuándo van ustedes a ir por Juvisy?

Su buen amigo,

Julio Camba.

El pequeño Rubén a quien se refiere Camba es el hijo del poeta con Francisca Sánchez, nacido en París el 2 de octubre de 1907. Juvisy era uno de los barrios más pintorescos de las afueras de París. Camba empezó frecuentándolo bastante y, finalmente, residió en él durante un tiempo.

\section{La Casa-Museo de Unamuno}

Publicada ya mi biografía de Camba recibí contestación de Inés Alonso Ayuso, de la Casa-Museo de Unamuno, en Salamanca, confirmando que existe en su archivo una sola carta de Julio Camba a don Miguel, con el siguiente texto:

$\mathrm{S}$ / c Plaza de Jesús, 3.

Sr. D. Miguel de Unamuno.

Querido Don Miguel:

El filósofo céltico saluda a su maestro ibero con el cariño y la admiración de siempre.

Julio Camba.

Madrid, 24 octubre de 1919.

La nota de Camba es, sin duda, su respuesta a una frase de Unamuno que se haría famosa años después gracias a haber sido reproducida, numerosas veces, en la solapa de los libros de Julio publicados en la Colección Austral de Espasa Calpe: «Camba, filósofo celta; yo, filósofo ibero. ¡Qué delicia para nuestros lectores celtiberos!» (López García, 2003, 236).

¿Qué hubiese pensado don Miguel de saber que Julio Camba, el autor de las páginas más breves y sintéticas de nuestra literatura contemporánea, le dedicaba a él por sus palabras de elogio una tarjeta de apenas dos líneas, y que, en cambio, enviaría a Nina Moreno de la Cova una carta de veinticuatro líneas, nada menos? Es verdad que a Nina «la echaba muchísimo de menos» y «la recordaba constantemente», cosa que no ocurriría 
-supongo- con el severo catedrático de Salamanca. Y es que, como vamos viendo, a Camba le interesaba mucho más la vida que la literatura, las chicas bonitas que las profundidades filosóficas... (En la Casa Museo Unamuno no se conserva, dedicado o sin dedicar, ni un solo libro de Julio. Quizá don Miguel leyó siempre los artículos de Camba publicados en la prensa y no en los libros.)

\section{El archivo de Pedro Sainz Rodríguez}

Uno de los mejores amigos de Julio Camba - por eso no debe extrañarnos la presencia de varias cartas suyas entre los papeles de su archivo, hoy en la Fundación Universitaria Española- fue el erudito y político monárquico, ministro de educación en el primer gobierno de Franco, Pedro Sainz Rodríguez. Son bien conocidas las condiciones de esta amistad. Sainz Rodríguez ha hablado de ella en su libro de memorias Testimonio y recuerdos -Barcelona, Planeta, 1978-y, especialmente, en Semblanzas -Barcelona, Planeta, 1988-, reproduciendo en este segundo libro tres cartas de Julio, escritas dos de ellas durante la Guerra Civil española.

Villanueva de Arosa (Pontevedra), 27-3-1938.

Sr. D. Pedro Sainz Rodríguez.

Querido Pedro:

No sabe V. bien cuánto me seduce la idea de pasar unos días en su compañía, charlar con V., examinar detenidamente los talentos culinarios de ese cordon bleu que V. ha tomado a su servicio y, como fin de fiesta, hincharme de dinero al poker, juego siempre un poco aleatorio en el café o el casino, pero nunca en casa de un hombre tan fiel observador como V. de las leyes de la hospitalidad. Desgraciadamente, en las circunstancias actuales no hay medio de viajar en tren y el viaje en avión está completamente fuera de mis posibilidades económicas. Tendré, por lo tanto, que esperar a que algún amigo vaya en coche, si no hasta Vitoria, por lo menos hasta Burgos, Valladolid, Salamanca o San Sebastián y, en cuanto se me presente la ocasión, hacia ahí iré sin vacilar ni un segundo. Hace falta, sin embargo, que V. me proporcione previamente un salvoconducto $y$, al efecto, le incluyo un par de fotografías con los siguientes datos:

Edad: 53 años

Profesión: Escritor

Lugar de nacimiento: Villanueva de Arosa (Pontevedra)

Nombre: Julio Camba Andreu... etc., etc.

No deje V. de enviarme este salvoconducto cuanto antes, cuanto más amplio, mejor, y, a ser posible, con autorización para pasar la fronte- 
ra, no sólo por ciertos proyectos profesionales que tengo y que ya le comunicaré a $\mathrm{V}$., sino también por si algún día podemos irnos juntos a darnos un gueuleton a Biarritz o San Juan de Luz.

Por lo que respecta a Victoriano García Martí parece que, de momento, lo más importante sería obtener su libertad provisional. Si V. puede hacer algo por él lo celebraré mucho así como también desearía que se interesase $\mathrm{V}$. por ese maestro de Marín a quien se refiere la nota adjunta. Es compadre de un gran amigo mío, y mientras yo esté en Galicia, no tendré más remedio que freírle a $\mathrm{V}$. con las peticiones de los compadres.

Y nada más ya que espero que nos veamos muy pronto. Precisamente Pepe Reboredo acaba de decirme que piensa irse a Burgos en coche hacia mediados de abril.

Un gran abrazo.

Su viejo amigo

Julio Camba.

Esta carta, copiada por Sainz Rodríguez en su libro Semblanzas, se puede ver, en bonita edición facsímil, en una carpeta que, con el título de Cartas a don Pedro, se publicó, sin pie de imprenta, sin lugar y sin año, hace ya algún tiempo y que conocen bien los libreros de viejo madrileños. Se trata de dos cuartillas de papel azul, dobladas, escritas a mano con tinta negra. La trascripción que hace Sainz Rodríguez es casi exacta; salvo alguna palabra que no ha entendido bien, y que ahora hemos corregido, no ha añadido ni quitado nada, por lo que suponemos que las otras dos cartas reproducidas abajo se ajustan también a los originales.

La siguiente carta que copia Sainz Rodríguez, más breve que la anterior, es sin embargo muy interesante para el biógrafo de Camba, por cuanto nos revela la generosidad y la inteligencia de Julio aparentando cierta desgana, desinterés y hasta cinismo a la hora de pedir un favor para sus amigos en situación difícil:

Villanueva de Arosa, 15 de mayo de 1938.

Querido Pedro:

$\mathrm{Va}$ a ser necesario que me escriba $\mathrm{Vd}$. una carta muy seria rogándome que no le envíe más recomendaciones de maestros. Si Vd. me lo ruega yo no tendré más remedio que acceder a su ruego pero, si no me lo ruega $\mathrm{Vd}$., dispóngase desde ahora a recibir en su despacho a todos los maestros de la provincia de Pontevedra quienes vendrán a mi casa con unos hijos más o menos auténticos a pedirme cartas para Vd. y no nos dejarán en paz al uno ni al otro. No sé cómo diablos se han enterado estos señores de que somos amigos y, sin fijarse en que yo no le pido a Vd. nada para mí, quieren que le pida todos los días cosas para ellos. 
Escríbame Vd. por lo tanto esa cartita, que nos servirá a ambos de escudo y protección y ja ver cuándo puedo ir por ahí! Tengo unas ganas enormes de charlar con Vd. pero hasta ahora, y como aquí no hay póker, todavía no me [ha] sido posible levantar el vuelo.

Un gran abrazo, Julio Camba.

La tercera y última de las cartas autógrafas que transcribe Sainz Rodríguez es casi diez años posterior. Observamos en ella el nerviosismo, casi la desesperación de Camba, ante la soledad veraniega:

\section{AVENIDA PALACE HOTEL [LISBONNE, PORTUGAL]}

Lisboa, 2 de agosto de 1947.

Sr. D. Pedro Sainz Rodríguez.

Querido amigo:

Sabía que estaba Vd. instalado en la Faz do Douro con la Vicenta, el Delfín y el Faisca, y también sabía que se había Vd. hecho socio de un club piscícola y se dedicaba con gran entusiasmo a extraer del mar fanecas, cachuchos, algas, zapatos viejos, etc., etc. Lo que ignoraba era su dirección y aún no estoy muy seguro de conocerla ahora, porque no sé si es el 49 de la rua do Veludo - mao de ferro em luva de veludo-o el 104 de Foz.

Como es natural, yo tengo unos grandes deseos de verle y me gustaría inmenso dar una vuelta por el Norte pero desgraciadamente me parece que voy a pasarme todo el verano en el Rocío, solo como una ostra, derritiéndome de calor, viendo desfilar a todo pasto bombeiros y más bombeiros por la Avenida de la Liberdade en conmemoración de la toma de Lisboa a los mouros... Quizá a mediados de septiembre pueda hacer una escapada por ahí, pero tal vez para esa fecha está Vd. ya de vuelta en la rua Herculano. En fin, ya veremos.

Aquí no queda ya ni una rata. Se han ido los Pastora. Se han ido los Cort. Se ha ido Ortega. Se ha ido todo Cristo. Yo hago cada vez una vida más aburrida y más estúpida.

Un gran abrazo,

Julio Camba.

\section{El archivo de la familia Pombo Fernández}

A finales del año 2005 Galicia Hoxe, página digital del periódico El Correo Gallego, ha publicado un interesante artículo de uno de los más entusiastas lectores de Camba, el escritor Benito Leiro Conde. Benito 
Leiro ha tenido la suerte de conocer, así nos lo cuenta en «A revelación íntima», una serie de cartas y papeles originales de los hermanos Julio y Francisco Camba, guardados en un baúl de la familia Pombo Fernández. Se trata en opinión de Leiro, que no parece conocer el archivo de Utrillo en Casa Ciriaco de Madrid, de un verdadero «tesoro cultural», de «la mayor colección de cartas manuscritas y papeles personales de Julio Camba». Compone el conjunto una colección de «treinta documentos rigurosamente inéditos que nos permiten entrar en el ámbito familiar y en el contorno más íntimo de los hermanos Camba». Lourdes Pombo y sus hermanos guardaban todo, celosamente, en un cofre, pero ahora, cincuenta años después, «consideran que dar a conocer estas cartas, tarjetas postales, fotografías y notas, puede servir como reconocimiento de la memoria y una contribución al estudio biográfico de Julio Camba y, en menor medida, de Francisco»».

Pastor Pombo Regás (1866-1952) fue el maestro de las primeras letras de Julio y el mejor amigo de la familia Camba. De hecho, como precisa Leiro, los padres de Julio, Manuel y Juana, fueron padrinos de pila de Pastor Pombo Ferro, hijo primogénito de Pastor Pombo.

Ambos hermanos Camba, pero sobre todo Julio, mantuvieron una entrañable relación de amistad con la familia Pombo. La casona y el estanco de don Pastor eran «como el segundo hogar del cronista cuando éste regresaba a Villanueva para reponer fuerzas tras alguno de sus frecuentes viajes. Allí escuchaba la radio, charlaba en animado diálogo y jugaba al tute con sus amigos»?.

Los manuscritos que Lourdes Pombo enseña a Benito Leiro demuestran, a lo que parece, un amistoso intercambio postal con su viejo maestro. Una de estas misivas, datada en San Sebastián en 1937, en plena Guerra Civil, comienza con «una muestra del proverbial sentido del humor cambiano»: "Querido Pastor: Tu carta debía estar toda impregnada de gérmenes, porque en cuanto la recibí pillé un catarro que no creo envidiase nada al tuyo. Ahora ya casi estoy bien, pero tuve fiebre y pasé más de quince días tosiendo como mi gato.» No sabemos si la carta termina ahí o si continúa ofreciendo Julio en ella noticias de su vida, pues Leiro no sigue copiando. Tampoco sabemos con seguridad si fue escrita en gallego o en castellano. Suponemos que está en español, aunque al publicar Leiro su artículo en gallego ha debido de traducirla, con un criterio más político que científico, a la suave y musical lengua hermana del castellano.

A continuación habla Leiro de varias cartas dirigidas por Julio a su «nai», Juana Andreu, interesantes porque en ellas se evidencia su «morriña» del pueblo y por contar diferentes recuerdos que le vienen a la mente en sus largas ausencias. Son cartas, datadas entre 1920 y 1940 , que expre- 
san la «saudade» de Camba por su tierra. Leiro cree en el interés e incluso en la importancia de estas cartas por cuanto los especialistas apenas hemos podido encontrar originales de Julio.

Hay otros documentos curiosos: Lourdes Pombo enseña a Leiro una foto postal manuscrita al dorso por el pintor Ignacio Zuloaga, gran amigo de Julio. Se ve en la foto -en blanco y negro- una insólita capea en el predio que el torero Juan Beimonte tenía en Utrera (Sevilla). La familia Pombo opina que hay que ordenar toda esta documentación y cree que aún se puede descubrir alguna que otra carta.

Aparece, por ejemplo, entre tantos y tan variados papeles, un comunicado oficial de la Universidad de Wisconsin, en 1940, solicitando a Julio tres ensayos para incluirlos en una antología de la literatura española.

En otra carta desde París, datada el 18 de noviembre de 1924, Julio Camba informa a su «nai» que va a embarcar en el trasatlántico Majestic rumbo a Nueva York. La tranquiliza explicándole que el barco es muy grande y seguro, de modo que nadie se marea a bordo. Y concreta: «Es tan largo como de la punta de Cabo hasta el Montiño». «Cualquier vilanovés -aclara Leiro Conde- entiende perfectamente las referencias geográficas que expresa Camba con este ejemplo un tanto exagerado»).

Posteriormente, Julio remite otra misiva desde el mismo buque para contarle que están a punto de atracar en el puerto de Nueva York.

Otra tarjeta postal a su «nai» describe un maravilloso viaje por Perú en 1924, invitado por el gobierno de aquel país. Leiro observa, lo cual nos agrada, que estas cartas evidencian por parte de Julio una sensibilidad y un cariño extraordinarios hacia su «nai»».

Van apareciendo así, poco a poco y en desorden, diferentes documentos que Leiro se apresura a estudiar. Así, por ejemplo, observa una carta de un admirador de Camba que le escribe desde Oviedo elogiando sus artículos. En el sobre figura el sello de la censura militar en plena Guerra Civil. También atisba Leiro otra carta, de una lectora «romanesa», pidiéndole al maestro de periodistas que traduzca al inglés La rana viaje$\mathrm{ra}$. Hay también varias fotos inéditas de Camba. En una se ve a Julio, ya maduro, paseando por Madrid con un matrimonio amigo.

Repara también Leiro en un interesante listado de la editorial EspasaCalpe -fue siempre Camba uno de sus escritores más rentables- «notificándole una liquidación de los derechos de autor que le corresponden por la venta de sus libros, especificando los títulos. Es una especie de albarán contable donde le indican al escritor qué le corresponde cobrar por las ventas de La Rana viajera, Aventuras de una peseta, La ciudad automática, etc». 
Otra curiosidad de este baúl mundo de la familia Pombo es la receta de un oftalmólogo madrileño en la cual se prescribe a Julio gafas para la lectura, concretando las dioptrías que tiene en cada ojo. "Anécdota vital -concluye Leiro- que refleja bien a las claras la importancia de esta magnífica colección documental que todavía nos guarda nuevas sorpresas». 


\section{BIBLIOGRAFÍA}

Álvarez Hernández, Dictino, Cartas de Rubén Darío. (Epistolario inédito del poeta con sus amigos españoles), Madrid, Taurus, 1963.

Amorós, Andrés, Correspondencia a Eduardo Marquina, Madrid, Castalia, 2005.

Gómez-Santos, Marino, «La soledad de Julio Camba», en AA.VV., Xornadas sobre Julio Camba, Santiago de Compostela, Xunta de Galicia, 2003, pp. 47-55.

LÁZARO, Ángel, «Último encuentro con Julio Camba», $A B C, 2$ de marzo, 1962.

López García, Pedro Ignacio, Julio Camba. El solitario del Palace, Madrid, Espasa Calpe, 2003.

López GARCía, Pedro Ignacio, «Epílogo» y «Documentación gráfica» a CAMBA, Julio, La casa de Lúculo o el arte de comer. (Nueva fisiologia del gusto), Madrid, Fundación Wellington, 2004.

Miranda, Sebastián, «Julio Camba», $A B C, 5$ de enero de 1975.

Sainz Rodríguez, Pedro, Semblanzas. Prólogo de José $M^{\mathrm{a}}$ de Areilza. Epílogo de Luis $\mathrm{M}^{\mathrm{a}}$ Anson. Barcelona, Planeta, 1988.

Sainz Rodríguez, Pedro, Cartas a don Pedro, s.l., s.a., s.n. [Carpeta con facsímiles de cartas] 